\title{
Formação em psicologia e educação inclusiva: um estudo transversal
}

\author{
Altemir José Gonçalves Barbosa \\ Carolina Ferreira Conti
}

\begin{abstract}
Resumo
Com o objetivo de efetuar um estudo transversal sobre a formação de psicólogos e a preparação recebida durante a graduação para atuar em escolas inclusivas, 163 estudantes de cinco períodos de dois cursos de Psicologia responderam a um questionário. Predominaram os participantes que não possuíam alguém com necessidade educacional especial na família. A maioria não teve, também, contato próximo com portadores de necessidades especiais. A maioria deles teve atividades e/ou disciplinas sobre inclusão escolar na graduação e estava insatisfeita ou indiferente quanto à preparação recebida para atuar em escolas inclusivas. Prevaleceram discentes que concordavam total ou parcialmente com a educação inclusiva. Constatou-se diferença significante entre os períodos somente no caso da inclusão escolar da necessidade educacional especial autismo. Há evidências de que a graduação em Psicologia não tem sido capaz de alterar o posicionamento dos estudantes quanto à educação inclusiva e de prepará-los para serem psicólogos escolares em escolas inclusivas.
\end{abstract}

Palavras-chave: Educação especial, inclusão escolar, psicologia escolar.

\section{Pre-service formation in psychology and inclusive education: a cross-sectional study}

\begin{abstract}
In order to develop a cross-sectional study on the psychologists' education and about the training in the undergraduate degree programs to work in inclusive schools, 163 students from five periods of two Psychology programs, answered a questionnaire. Participants who did not have someone with special educational needs in family were prevalent. Most students did not also had close relationship with these people. Most of them had activities and/or classes about school inclusion in undergraduate programs and were dissatisfied or indifferent with the training received to perform in inclusive schools. Students who agree totally or agree with inclusive education predominated. There was significant difference between the periods, only on the inclusion school of the special educational need autism they differed. There are evidences that the undergraduate Psychology programs have not been able to change the students' opinions about the inclusive education and to prepare them to be school psychologists in the inclusive schools.
\end{abstract}

Key words: Special education, school inclusion, school psychology.

\section{Formación en psicología y educación inclusiva: un estudio transversal}

\section{Resumen}

Con el objetivo de realizar estudio transversal sobre la formación de psicólogos y la preparación recibida durante la carrera de pre-grado para actuar en escuelas inclusivas, se solicitó a 163 estudiantes de cinco períodos de dos facultades de Psicología que respondieran un cuestionario. Predominaron los participantes que no poseían familiares con necesidades educacionales especiales. La mayoría tampoco tuvo contacto próximo con portadores de necesidades especiales. La mayoría tuvo actividades y/o cursos sobre inclusión escolar durante la carrera y estaba insatisfecha o indiferente en relación a la preparación recibida para actuar en escuelas inclusivas. Prevalecieron estudiantes que estaban totalmente de acuerdo o de acuerdo parcialmente con la educación inclusiva. Se constató diferencia significante entre los períodos solamente en el caso da inclusión escolar de la necesidad educacional especial - autismo. Existen evidencias de que la formación de pre-grado en Psicología no ha sido capaz de alterar la posición de los estudiantes en lo que se refiere a educación inclusiva ni de prepararlos para que sean psicólogos escolares en escuelas inclusivas.

Palabras Claves: Necesidades educacionales especiales; inclusión escolar; psicólogo escolar; enseñanza de Psicología. 


\section{Introdução}

Inicialmente, é preciso destacar que, embora possam ser efetuadas diferenciações entre escola inclusiva, educação inclusiva e inclusão escolar, no presente texto essas expressões serão consideradas sinônimas. Elas, no presente contexto, fazem menção ao processo de acolher, manter e promover o desenvolvimento de pessoas com necessidades educacionais especiais (NEE) em salas de aula comuns de escolares regulares. Ressalta-se, também, que o conceito de NEE tem sido alvo de muitas controvérsias (ver, por exemplo, González, 2002; Mitjáns Martínez, 2005) e que será adotada a perspectiva da Declaração de Salamanca, a qual se refere "a todas aquelas crianças ou jovens cujas necessidades educacionais especiais se originam em função de deficiências ou dificuldades de aprendizagem" (UNESCO, 1994). Acrescenta-se, ainda, que, apesar das limitações, especialmente por se tratar de um sistema nosográfico, foi adotada a classificação de NEE do Censo Escolar de 2006 (INEP, 2006) para operacionalizar esse construto no instrumento de coleta de dados, uma vez que as categorias por ela propostas têm sido amplamente apropriadas por leigos e, até mesmo, especialistas.

De acordo com a Declaração de Salamanca (UNESCO, 1994), que é considerada um marco histórico da educação inclusiva, as escolas devem acolher todas as crianças, independentemente de suas condições físicas, intelectuais, sociais, emocionais, linguísticas e outras. A inclusão exige mudanças na estrutura da sociedade e da própria educação escolar (Kafrouni \& Pan, 2001). Na escola inclusiva, as diferenças não devem constituir um fator de exclusão, pois cabe a ela respeitar e acolher a diversidade humana, bem como se modificar para propiciar o desenvolvimento de quaisquer indivíduos, independentemente de seus déficits ou necessidades.

Segundo Hastings e Oakford (2003), os professores são fundamentais para se obter sucesso neste processo. É o professor que pode criar condições favoráveis para a aceitação do aluno com NEE pelos colegas da classe, além de favorecer o convívio cooperativo, solidário e produtivo na sala de aula. Professores que são favoráveis à inclusão de alunos com NEE usam mais frequentemente estratégias de ensino consideradas inclusivas (Omote, 2005).

A atitude dos professores em relação à inclusão depende de diferentes variáveis, como a natureza do comprometimento e a série escolar que o aluno com NEE frequenta. Os professores são mais favoráveis à inclusão de alunos com deficiência física do que à inclusão de alunos com distúrbios emocionais e comportamentais. Além disso, a inclusão desses alunos nas séries iniciais do processo de aprendizagem é mais bem aceita que nas séries mais avançadas (Omote, 2005).

Além de professores, a escola inclusiva demanda o apoio interno e externo de outros profissionais. Conforme a Declaração de Salamanca, "a provisão de serviços de apoio é de fundamental importância para o sucesso de políticas educacionais inclusivas. A experiência sugere que servi- ços educacionais se beneficiariam significativamente caso maiores esforços fossem feitos para assegurar o ótimo uso de todo o conhecimento e recursos disponíveis" (UNESCO, 1994).

Esses profissionais podem ser, por exemplo, outros professores especializados em educação especial e/ ou psicólogos escolares. Mendes (2006) apresenta formas de colaboração bastante úteis para a inclusão entre os docentes das salas de aula regulares e os dois especialistas mencionados anteriormente.

A formação acadêmica de profissionais que lidam com processo inclusivo é fundamental (Angelides, Stylianou, \& Gibbs, 2006; Carroll, Forlin, \& Jobling, 2003; Voltz, 2001), sejam eles professores, psicólogos ou profissionais de qualquer outra área. Além de considerar os conhecimentos técnicos e teóricos para lidar com esses alunos, os cursos de graduação também devem ser capazes de desenvolver atitudes positivas, princípios éticos e compromisso social dos futuros profissionais em relação a uma escola que acoIha e promova o desenvolvimento de todos os alunos, com e sem NEE. A ausência destas características pode paralisar o processo inclusivo, ainda que as habilidades e competências teórico-técnicas estejam presentes.

De acordo com as Diretrizes Curriculares para os Cursos de Graduação em Psicologia (Conselho Nacional de Educação, 2004), as instituições que apresentam graduação nessa área devem assegurar aos discentes uma formação baseada na compreensão crítica dos fenômenos sociais, econômicos, culturais e políticos do país. Além disso, os futuros psicólogos devem ser capazes de atuar em diferentes contextos, levando em consideração os aspectos sociais e os direitos humanos e tendo em vista a promoção da qualidade de vida dos indivíduos, grupos, organizações e comunidades (Conselho Nacional de Educação, 2004).

A formação em Psicologia Escolar - que, dentre as diversas especialidades da área de Psicologia, é aquela que lida mais diretamente com estudantes com NEE - tem sido alvo de alguns estudos (Bariani, Buin, Barros, \& Escher, 2004; Neves, Almeida, Chaperman, \& Batista, 2002). Porém, pouca atenção tem sido dada à capacitação para atuar em escolas inclusivas.

Ao considerar a atuação de psicólogos escolares em escolas inclusivas, Mitjáns Martínez (2005) destaca que a concepção de Psicologia Escolar destes profissionais deve ser entendida de forma ampla, no sentido de integrar o conhecimento psicológico para melhor compreender os processos educativos que se dão no contexto escolar. De acordo com Engelbrecht (2004), a formação de habilidades e competências para a prática de psicólogos escolares deve ser desenvolvida com o intuito de favorecer ações holísticas de prevenção e promoção de saúde, voltadas para indivíduos, escolas e comunidade. Para os autores, o psicólogo escolar não deve ser preparado para intervir somente em nível individual (vide, também, Andrada, 2005), mas de forma sistêmica a fim de planejar e executar programas mais amplos. Assim, ele pode contribuir para o estabelecimento de ambientes positivos de aprendizagem, nos quais todos 
os alunos possam, mesmo diante da diversidade, aprender (Engelbrecht, 2004).

Mitjáns Martínez (2005), baseada em estudos exploratórios, afirma que os profissionais da educação com os quais tem trabalhado, inclusive os psicólogos, interpretam a inclusão como a incorporação de um segmento restrito de alunos nas escolas regulares aos quais são fornecidos apoios necessários para sua aprendizagem, como recursos tecnológicos, professores especializados, serviços de apoio etc. Desta forma, a inclusão se dá de maneira reduzida a um grupo específico e restrito de alunos, os discentes com NEE, não levando em consideração outros grupos socialmente excluídos, como os negros e pobres, que, muitas vezes, principalmente nas escolas públicas, são maioria. Além disso, a preocupação exagerada com alunos com NEE deixa de lado mudanças imprescindíveis nas concepções de educação inclusiva e nas estratégias educativas que devem operar na escola para que, de fato, ocorra uma efetiva inclusão (Mitjáns Martínez, 2005).

Um passo importante no sentido de "trazer à tona" o debate sobre a inclusão escolar e a atuação dos psicólogos foi dado pelo Conselho Federal de Psicologia recentemente. Trata-se da Campanha "Educação Inclusiva - Direitos Humanos na Escola!", iniciada em 2003 (Conselho Federal de Psicologia, 2004).

Dentre outros desdobramentos, a campanha deu origem à obra "Psicologia e Direitos Humanos: educação inclusiva, direitos humanos na escola" (Machado e cols., 2005). $\mathrm{Na}$ apresentação desta obra, Bock (2005) destaca que, durante anos, no Brasil, a escola não levou em consideração a realidade de seus alunos. Exigia-se deles uma adaptação aos critérios escolares, buscava-se uma educação homogeneizadora. Por muito tempo, a Psicologia colaborou para a construção desse papel excludente da escola brasileira. Segundo a autora, a Psicologia pode e deve reverter esse papel ao se inserir na escola e na educação, colaborando em um processo que inclui e do qual todos os alunos possam se beneficiar, mesmo diante das diversidades e individualidades. Para isso, a Psicologia precisa rever teorias, atitudes e práticas.

Também em decorrência desta campanha, o Conselho instituiu, em 2006, o prêmio "Educação inclusiva: experiências profissionais em Psicologia". Ainda que reduza significativamente o âmbito da educação inclusiva, isto é, foque a deficiência, o objetivo da proposta coaduna a perspectiva de se ter escolas inclusivas, uma vez que almeja dar visibilidade a experiências bem sucedidas de educação inclusiva desenvolvidas por psicólogos que tenham contribuído para a promoção e defesa de uma educação que cumpra seu caráter público, universal e de qualidade para todos, promovendo igualdade de acesso e permanência na escola de pessoas que têm sido excluídas por serem consideradas deficientes (Conselho Federal de Psicologia, 2006).

Ainda no campo das práticas profissionais em Psicologia Escolar inclusiva, merece destaque a obra "Inclusão escolar: travessias” (Colli \& Kupfer, 2005). O Grupo Ponte, a partir do trabalho de uma equipe interdisciplinar, favorece a inclusão da criança psicótica ao promover seu encontro com o professor. Por meio desse projeto, muitos alunos que estavam em salas especiais puderam retomar seu desenvolvimento em salas regulares. Dessa forma, os alunos incluídos podem usufruir, à sua maneira, do laço social. Com o trabalho desse grupo, o encontro do professor com a criança, que antes era considerado angustiante, desconfortante e que muitas vezes paralisava o processo de aprendizagem, tornou-se mais produtivo. A experiência do grupo tem evidenciado que tanto a criança psicótica quanto seus colegas de sala e os educadores se beneficiam da inclusão (Colli, 2005).

\section{Objetivos}

O objetivo geral da pesquisa foi efetuar um estudo transversal sobre a formação de psicólogos e a preparação recebida em cursos de graduação para atuar em escolas inclusivas. Especificamente, as metas foram: caracterizar a experiência pessoal e acadêmica de estudantes de Psicologia com pessoas com NEE; descrever os pontos de vista dos participantes quanto à formação ofertada pelos cursos de graduação para atuar em escolas inclusivas; identificar o posicionamento dos discentes em relação à inclusão escolar em geral e no que se refere às NEE específicas; e comparar os objetivos específicos anteriores considerando os períodos em que os estudantes estavam.

\section{Método}

\section{Participantes}

Participaram da pesquisa aproximadamente 163 estudantes universitários de duas Instituições de Ensino Superior (IES) de uma cidade do interior de Minas Gerais, sendo $85(52,15 \%)$ de uma universidade pública e $78(47,85 \%)$ do ensino privado (Tabela 1). Quanto às IES, havia apenas duas que tinham o curso-alvo na cidade quando da coleta de dados, sendo uma universidade privada e uma pública. Assim, a amostra foi do tipo não probabilística, intencional no caso das IES e acidental para os discentes. Foram incluídos estudantes que estavam regularmente matriculados nas turmas e IES-alvo; estudavam em períodos correspondentes, pois o curso de Psicologia de uma universidade era anual e da outra, semestral; estavam presentes no momento da aplicação (vide Procedimento); e consentiram livre e esclarecidamente com a pesquisa. Foram excluídos somente alunos menores de 18 anos, uma vez que dependiam da autorização de um responsável legal. 
Tabela 1. Caracterização demográfica da amostra.

\begin{tabular}{|c|c|c|c|c|c|c|c|c|c|c|c|c|}
\hline \multirow{3}{*}{ Variáveis } & \multicolumn{10}{|c|}{ Períodos } & \multirow{2}{*}{\multicolumn{2}{|c|}{ Total }} \\
\hline & \multicolumn{2}{|c|}{$2^{\circ}$} & \multicolumn{2}{|c|}{$4^{\circ}$} & \multicolumn{2}{|c|}{$6^{\circ}$} & \multicolumn{2}{|c|}{$8^{\circ}$} & \multicolumn{2}{|c|}{$10^{\circ}$} & & \\
\hline & $\mathrm{n}$ & $\%$ & $\mathrm{~N}$ & $\%$ & $\mathrm{n}$ & $\%$ & $\mathrm{~N}$ & $\%$ & $\mathrm{n}$ & $\%$ & $\mathrm{n}$ & $\%$ \\
\hline \multicolumn{13}{|l|}{ Tipo de IES } \\
\hline Privada & 26 & 50,98 & 22 & 57,89 & 11 & 36,67 & 4 & 18,18 & 15 & 68,18 & 78 & 47,85 \\
\hline Pública & 25 & 49,02 & 16 & 42,11 & 19 & 63,33 & 18 & 81,82 & 7 & 31,82 & 85 & 52,15 \\
\hline Total & 51 & 100 & 38 & 100 & 30 & 100 & 22 & 100 & 22 & 100 & 163 & 100 \\
\hline \multicolumn{13}{|l|}{ Gênero } \\
\hline Masculino & 8 & 15,69 & 7 & 19,44 & 7 & 24,14 & 2 & 9,09 & 5 & 22,73 & 29 & 18,13 \\
\hline Feminino & 43 & 84,31 & 29 & 80,56 & 22 & 75,86 & 20 & 90,91 & 17 & 77,27 & 131 & 81,88 \\
\hline Total & 51 & 100 & 36 & 100 & 29 & 100 & 22 & 100 & 22 & 100 & 160 & 100 \\
\hline \multicolumn{13}{|l|}{ Possui NEE } \\
\hline Não & 48 & 96,00 & 37 & 100,00 & 29 & 96,67 & 21 & 100,00 & 21 & 95,45 & 156 & 97,50 \\
\hline Sim & 2 & 4,00 & - & - & 1 & 3,33 & - & - & 1 & 4,55 & 4 & 2,50 \\
\hline Total & 50 & 100 & 37 & 100 & 30 & 100 & 21 & 100 & 22 & 100 & 160 & 100 \\
\hline \multirow[t]{2}{*}{ Idade } & $\bar{X}$ & \pm & $\bar{X}$ & \pm & $\bar{X}$ & \pm & $\bar{X}$ & \pm & $\overline{\mathrm{X}}$ & \pm & $\overline{\mathrm{X}}$ & \pm \\
\hline & 20,67 & 5,93 & 22,97 & 6,76 & 22,43 & 3,67 & 23,82 & 7,09 & 25,91 & 4,50 & 22,66 & 5,98 \\
\hline
\end{tabular}

\section{Materiais}

Foi utilizado um questionário que permitiu uma caracterização demográfica da mostra (idade, gênero etc.), uma descrição de variáveis relacionadas às experiências pessoais (p. ex., possuir uma pessoa com NEE na família) e de formação (p. ex., estágio) com pessoas com NEE e uma identificação dos pontos de vista dos participantes em relação à inclusão escolar e à preparação para atuar em escolas inclusivas. Reitera-se que, para orientar as respostas dos participantes quanto ao que considerar NEE, empregou-se a classificação do MEC (INEP, 2006), mesmo ciente das limitações da mesma, já mencionadas anteriormente.

Além do questionário, também foram aplicadas duas escalas de atitudes. Porém, devido às limitações da dimensão de um artigo, são apresentados e analisados no presente texto somente os resultados referentes ao primeiro instrumento.

Também compuseram os materiais utilizados um termo de consentimento livre e esclarecido para os estudantes universitários e um termo de autorização por parte dos coordenadores dos cursos-alvo. O primeiro foi elaborado com base na Resolução 196/96 (CONEP, 1996).

\section{Procedimento}

Como denotado anteriormente, esta pesquisa respeitou os procedimentos éticos para estudos com seres humanos estabelecidos pela resolução 196/96 (CONEP, 1996), sendo aprovada por um Comitê de Ética em Pesquisa com seres humanos (CAAE 0132.0.180.000-06). A coleta de dados foi agendada de acordo com os horários disponíveis pelas instituições-alvo e precedida pela obtenção do consentimento livre e esclarecido por parte dos estudantes universitários. As instruções sobre a pesquisa e sobre o preenchimento do questionário e das escalas foram dadas antes que se iniciasse o preenchimento dos termos e dos instrumentos, nessa sequência. A aplicação do instrumento foi realizada coletivamente sem controle de tempo.

A análise dos dados foi essencialmente quantitativa. O nível de significância adotado foi de 5 \% por omissão.

\section{Resultados e Discussão}

A Tabela 2 sintetiza a experiência pessoal e acadêmica dos participantes com pessoas com NEE. Entre os 159 estudantes que responderam à questão referente à presença de um indivíduo com NEE na família, prevaleceram aqueles que afirmaram não ter membros com esta condição no 
Tabela 2. Experiências pessoais e acadêmicas com pessoas com NEE ou com inclusão escolar por período.

\begin{tabular}{|c|c|c|c|c|c|c|c|c|c|c|c|c|}
\hline \multirow{3}{*}{ Variáveis } & \multicolumn{10}{|c|}{ Períodos } & \multirow{2}{*}{\multicolumn{2}{|c|}{ Total }} \\
\hline & \multicolumn{2}{|c|}{$2^{\circ}$} & \multicolumn{2}{|c|}{$4^{\circ}$} & \multicolumn{2}{|c|}{$6^{\circ}$} & \multicolumn{2}{|c|}{$8^{\circ}$} & \multicolumn{2}{|c|}{$10^{\circ}$} & & \\
\hline & $\mathrm{N}$ & $\%$ & $\mathrm{~N}$ & $\%$ & $\mathrm{n}$ & $\%$ & $\mathrm{n}$ & $\%$ & $\mathrm{n}$ & $\%$ & $\mathrm{n}$ & $\%$ \\
\hline \multicolumn{13}{|l|}{ Na família } \\
\hline Sim & 5 & 10,64 & 6 & 15,79 & 7 & 23,33 & 6 & 27,27 & 4 & 18,18 & 28 & 17,61 \\
\hline Não & 42 & 89,36 & 32 & 84,21 & 23 & 76,67 & 16 & 72,73 & 18 & 81,82 & 131 & 82,39 \\
\hline Total & 47 & 100 & 38 & 100 & 30 & 100 & 22 & 100 & 22 & 100 & 159 & 100 \\
\hline \multicolumn{13}{|c|}{ Contato próximo } \\
\hline Sim & 36 & 72,00 & 32 & 84,21 & 25 & 83,33 & 19 & 86,36 & 15 & 71,43 & 127 & 78,88 \\
\hline Não & 14 & 28,00 & 6 & 15,79 & 5 & 16,67 & 3 & 13,64 & 6 & 28,57 & 34 & 21,12 \\
\hline Total & 50 & 100 & 38 & 100 & 30 & 100 & 22 & 100 & 21 & 100 & 161 & 100 \\
\hline \multicolumn{13}{|c|}{ Em sala de aula } \\
\hline Sim & 30 & 60,00 & 10 & 26,32 & 15 & 50,00 & 8 & 36,36 & 6 & 27,27 & 69 & 42,59 \\
\hline Não & 20 & 40,00 & 28 & 73,68 & 15 & 50,00 & 14 & 63,64 & 16 & 72,73 & 93 & 57,41 \\
\hline Total & 50 & 100 & 38 & 100 & 30 & 100 & 22 & 100 & 22 & 100 & 162 & 100 \\
\hline \multicolumn{13}{|c|}{ Atividades e/ou disciplinas sobre inclusão escolar no curso } \\
\hline Sim & 1 & 1,96 & 24 & 63,16 & 30 & 100 & 22 & 100 & 21 & 95,45 & 98 & 60,12 \\
\hline Não & 50 & 98,04 & 14 & 36,84 & - & - & - & - & 1 & 4,55 & 65 & 39,88 \\
\hline Total & 51 & 100 & 38 & 100 & 30 & 100 & 22 & 100 & 22 & 100 & 163 & 100 \\
\hline \multicolumn{13}{|c|}{ Atividades extracurriculares } \\
\hline Sim & 5 & 9,80 & 16 & 42,11 & 5 & 16,67 & 11 & 50,00 & 4 & 18,18 & 41 & 25,15 \\
\hline Não & 46 & 90,20 & 22 & 57,89 & 25 & 83,33 & 11 & 50,00 & 18 & 81,82 & 122 & 74,85 \\
\hline Total & 51 & 100 & 38 & 100 & 30 & 100 & 22 & 100 & 22 & 100 & 163 & 100 \\
\hline
\end{tabular}

grupo familiar ( $\left.n=131 ; 82,39 \% ; \chi_{\circ}^{2}=66,72 ; g l=1 ; p=0,00\right)$. Quando são considerados os períodos, verificou-se que não há diferença entre eles quanto a este aspecto $\left(\chi_{0}^{2}=3,76\right.$; $\mathrm{gl}=4 ; \mathrm{p}=0,44)$.

No que se refere ao contato próximo com indivíduos com NEE, a maioria $\left(\chi_{0}^{2}=53,72 ; \mathrm{gl}=1 ; p=0,00\right)$ dos estudantes afirmou que já teve esse tipo de experiência pessoal. Foi verificado também que não existe diferença neste aspecto ao se considerar os períodos $\left(\chi_{o}^{2}=3,87 ; \mathrm{gl}=4 ; p=0,42\right)$. Não foi obtida diferença significante $\left(\chi_{0}^{2}=3,56 ; \mathrm{gl}=\right.$ $1 ; p=0,06)$ ao se comparar a proporção de discentes que já tiveram colegas com NEE em sala e que não tiveram. Porém, quando se considera o período, foi verificada diferença significante $\left(\chi_{0}^{2}=13,45 ; g l=4 ; p=0,01\right)$, sendo que, no segundo $\left(\chi_{0}^{2}=2 ; g l=1 ; p=0,16\right)$, no sexto $\left(\chi_{0}^{2}=00,00\right.$; $g l=1 ; p=1)$ e no oitavo $\left(\chi_{\circ}^{2}=1,64 ; g l=1 ; p=0,20\right)$ períodos, não foram constatadas diferenças significantes entre os estudantes que tiveram e não tiveram em suas salas um colega com NEE. Porém, no quarto $\left(\chi^{2}{ }_{0}=8,53 ; \mathrm{gl}=1\right.$; $p=0,00)$ e no décimo $\left(\chi_{o}^{2}=4,55 ; g l=1 ; p=0,03\right)$ períodos, prevaleceram os estudantes que não tiveram esse tipo de experiência acadêmica.

Os resultados descritos nos parágrafos anteriores têm proximidade com o que se revelou no último censo do IBGE (2000), isto é, 14,5\% da população brasileira apresentam algum tipo de deficiência, sendo que, no estado de Minas Gerais, a porcentagem é de $14,89 \%$. Entre os participantes da presente pesquisa, $17,61 \%$ tinham uma ou mais pessoas com NEE na família, podendo atribuir-se a diferença entre os dois escores à presença de certas NEE que não são investigadas pelo censo - principalmente aquelas que não são "deficiências" - e, ainda, à "margem de erro" que caracteriza as pesquisas científicas.

Desses $14,89 \%$ de indivíduos com deficiência no estado de Minas Gerais, 9,13\% tinham idade entre 5 e 17 anos; assim, poderiam estar frequentando classes comuns 
de escolas regulares. Na faixa etária entre 18 e 24 anos, ou seja, a que mais se aproxima dos indivíduos do presente estudo, havia 6,36\% (IBGE, 2000).

É importante ressaltar que houve um aumento da inclusão escolar nos últimos anos. O Censo Escolar (MEC/ INEP, 2006) revelou que, em $2002,80,5 \%$ das pessoas com NEE estudavam em escolas e classes especiais. Já em 2006 esse número caiu para $57,0 \%$, sendo que a maioria das matrículas na educação inclusiva é realizada nas escolas públicas (MEC/INEP, 2006).

As experiências pessoais e acadêmicas dos estudantes de Psicologia com indivíduos com NEE são importantes, pois, dentre outros fatores, podem influenciar as atitudes em relação a esses indivíduos e à inclusão escolar dos mesmos. Johnson e Howell (2005) afirmam que as atitudes em relação à educação inclusiva podem ser formadas a partir de experiências diretas. É importante ressaltar que pessoas que têm ou tiveram contato próximo com indivíduos com NEE tendem a possuir atitudes mais favoráveis em vários sentidos em relação à inclusão escolar (Carroll e cols., 2003).

Como exposto anteriormente, a graduação deve garantir tanto experiências acadêmicas - teoria e prática - para que os futuros profissionais possam lidar de forma adequada com os indivíduos com NEE (Angelides e cols., 2006; Carroll e cols., 2003; Voltz, 2001), quanto fornecer outras oportunidades para que eles desenvolvam atitudes favoráveis à educação inclusiva. Observou-se que predominaram $\left(\chi_{\circ}^{2}=6,68 ; \mathrm{gl}=1 ; p=0,01\right)$ estudantes que tiveram em seus cursos de graduação em Psicologia atividades e/ ou disciplinas sobre inclusão escolar. Também foram observadas diferenças entre os períodos $\left(\chi^{2}{ }_{0}=118,05 ; \mathrm{gl}=4 ; p=\right.$ $0,00)$, mais especificamente entre o segundo e os demais. Neste caso, como esperado, 98,04\% não tiveram atividades e/ou disciplinas sobre educação inclusiva.

Ainda quanto às experiências com pessoas com NEE e com inclusão escolar, foi observado que predominaram $\left(\chi_{o}^{2}=40,25 ; \mathrm{gl}=1 ; p=0,00\right)$ estudantes que não fizeram atividade extracurricular relacionada à educação inclusiva durante a graduação. Quando são considerados os períodos, verificou-se diferença significante entre eles $\left(\chi_{0}^{2}=21,11\right.$; gl $=4 ; p=0,00)$. Este resultado parece ser decorrente do fato de no quarto $(42,11 \%)$ e no oitavo $(50 \%)$ períodos haver uma proporção maior de discentes que fizeram alguma atividade extracurricular relacionada à educação inclusiva.

De acordo com o Conselho Federal de Psicologia (2001), a área de Psicologia Escolar é a $4^{\mathrm{a}}$ área de atuação escolhida pelos psicólogos. Porém, Senna e Almeida (2005) destacam que os cursos de formação inicial de Psicologia têm pouca oferta de estágios na área escolar e que esta área tem atraído cada vez menos os estudantes. Afirmam, também, que a formação do psicólogo escolar ainda está defasada.

Alguns resultados obtidos parecem corroborar as ponderações de Senna e Almeida (2005). Ainda que seja algo isolado, o fato de um discente do décimo período não ter tido sequer uma atividade e/ou disciplina sobre educação inclusiva ao longo de sua formação denota, de certa forma, a defasagem na formação do psicólogo escolar. Também é preciso destacar que a área de Educação Especial é uma das principais fontes de atividades extracurriculares para graduandos de Psicologia, mas parece que poucos tiveram essa experiência não acadêmica de grande valor para o futuro psicólogo.

Outro indício dos déficits da formação em Psicologia Escolar ficou evidente na análise da satisfação dos estudantes de Psicologia quanto à formação para atuar em escolas inclusivas (Figura 1). Os graduandos, de modo geral, não estão nem satisfeitos nem insatisfeitos ( $\bar{X}=3,12 \pm 0,92)$, não sendo encontradas diferenças significantes entre os períodos $(\mathrm{F}=0,71 ; \mathrm{gl}=4 ; p=0,59)$. Ressalta-se que o nível de satisfação foi mensurado a partir de uma questão com cinco pontos de resposta, sendo que o número "três" correspondia a um ponto neutro.

Figura 1. Nível de satisfação dos graduandos em Psicologia em relação à formação recebida para atuar em escolas inclusivas.

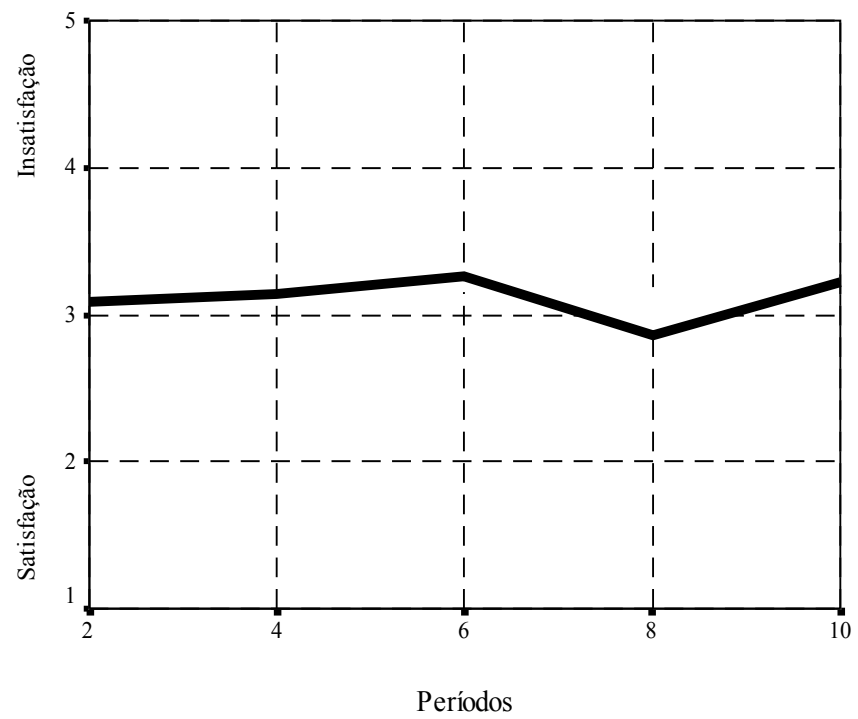

Se o percentual de "nem satisfeitos nem insatisfeitos" ( $n=65 ; 41,14 \%$ ) for somado ao de alunos com algum tipo de insatisfação ( $n=53 ; 33,54 \%$ ), tem-se um resultado que é ainda mais preocupante, uma vez que teremos mais de $70 \%$ dos estudantes insatisfeitos ou, de certo modo, indiferentes em relação à preparação recebida na graduação para atuarem em escolas inclusivas. Senna e Almeida (2005) afirmam que, para a melhoria da formação em Psicologia Escolar, são necessárias mudanças na estrutura curricular dos cursos de graduação e nos aspectos práticos dessa formação. Assim, seria possível obter uma melhor compreensão da realidade educacional brasileira e de seus problemas e a reflexão sobre alternativas mais efetivas de atuação do psicólogo escolar (Senna \& Almeida, 2005).

A Figura 2 apresenta o nível de concordância dos participantes quanto à inclusão escolar por períodos. Não foram obtidas diferenças estatisticamente significativas entre eles $(F=0,90 ; g l=4 ; p=0,46)$. A média geral dos períodos 
$(\bar{X}=1,79 \pm 0,84)$ pode ser considerada positiva, pois, da mesma forma que o nível de satisfação com a formação para atuar em escolas inclusivas, empregaram-se cinco pontos, sendo que "um" indicava concordância total e "cinco", discordância total.

Figura 2: Nível de concordância de graduandos em Psicologia quanto à inclusão escolar por período.

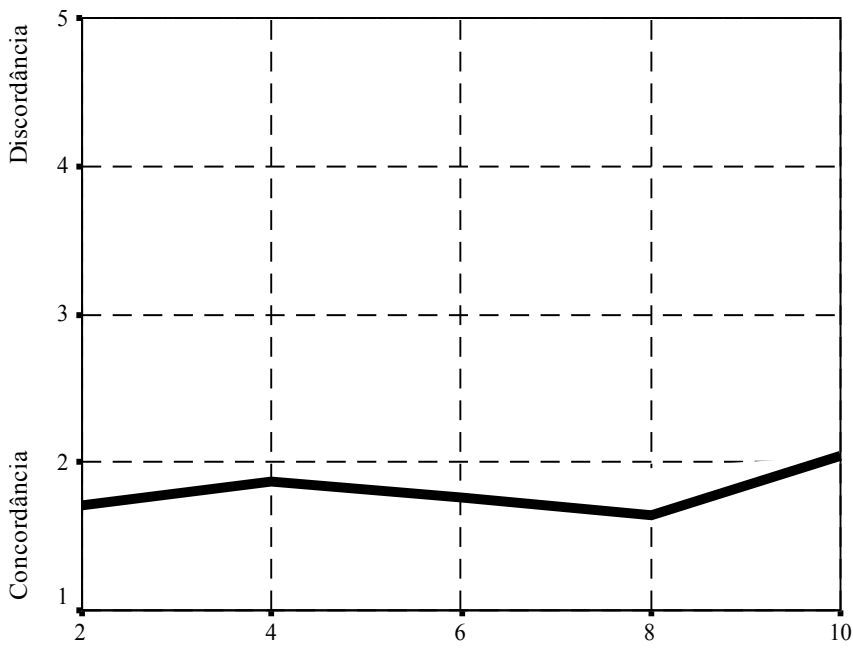

Períodos

O resultado descrito no parágrafo anterior permite inferir, por um lado, que os futuros psicólogos tendem a possuir atitudes favoráveis quanto à inclusão escolar. Há que se reiterar que, ao se tratar do processo de inclusão escolar, as barreiras atitudinais - atitudes negativas - têm sido um dos principais impedimentos para o estabelecimento de sistemas educacionais inclusivos. As atitudes, de acordo com Ajzen (2001), são vistas geralmente como avaliações sumárias dos objetos nas quais estes são analisados ao longo de uma dimensão que varia do positivo ao negativo. Essa avaliação cognitiva-afetiva gera uma disposição para responder, dependendo do objeto, de maneira favorável ou desfavorável (Ajzen, 2001). Fica evidente que as atitudes atuam na mediação cognitiva e afetiva do comportamento e podem, desta forma, facilitá-lo ou obstaculizá-lo.

Por outro lado, evidencia-se que a formação não é necessariamente responsável pela tendência de os graduandos concordarem com a inserção de pessoas com NEE em salas comuns da rede regular de ensino. Corrobora-se, assim, que as opiniões e atitudes têm um caráter social (Crano \& Prislin, 2006) que extrapola o contexto do Curso de Psicologia. Fica evidente, também, a dificuldade que os cursos da área têm para ir além de conteúdo e mudar atitudes.

As Tabelas 3 e 4 resumem, respectivamente, o nível de concordância de graduandos em Psicologia quanto à inclusão escolar das NEE elencadas no censo educacional do Ministério da Educação (MEC/INEP, 2006) e a ANOVA entre os períodos. Somente no caso do autismo foi constada diferença significante entre os períodos $(\mathrm{F}=3,13 ; \mathrm{gl}=4 ; p=0,02)$, sendo que o teste de Post Hoc com Tukey revelou que o décimo período se posiciona de forma mais negativa que o segundo $(p=0,02)$, o quarto $(p=0,02)$ e o oitavo $(p=0,03)$ períodos, mas não discrepa do sexto $(p=0,07)$.

Esse resultado é preocupante, já que, na turma que está concluindo a graduação em Psicologia, existem mais discentes que discordam da inclusão de pessoas com autismo na escola. É provável que esses discentes já estejam hoje no mercado de trabalho, e, como a graduação em Psicologia no Brasil tem caráter generalista, um ou outro pode estar trabalhando ou vir a trabalhar em escolas que devem matricular alunos com essa NEE, pois, de acordo com a Declaração de Salamanca, "as escolas deveriam acomodar todas as crianças independentemente de suas condições físicas, intelectuais, sociais, emocionais, linguísticas ou outras. Todas as crianças devem aprender juntas, sempre que possível, independente de quaisquer dificuldades ou diferenças que elas possam ter" (UNESCO, 1994).

Tabela 3. Nível de concordância de graduandos em Psicologia quanto à inclusão escolar de NEE por período.

\begin{tabular}{|c|c|c|c|c|c|c|c|c|c|c|c|c|}
\hline \multirow{3}{*}{ NEE } & \multicolumn{10}{|c|}{ Períodos } & \multirow{2}{*}{\multicolumn{2}{|c|}{ Total }} \\
\hline & \multicolumn{2}{|c|}{$2^{\circ}$} & \multicolumn{2}{|c|}{$4^{\circ}$} & \multicolumn{2}{|c|}{$6^{\circ}$} & \multicolumn{2}{|c|}{$8^{\circ}$} & \multicolumn{2}{|c|}{$10^{\circ}$} & & \\
\hline & $\bar{X}$ & \pm & $\bar{X}$ & \pm & $\bar{X}$ & \pm & $\bar{X}$ & \pm & $\bar{X}$ & \pm & $\bar{X}$ & \pm \\
\hline Autismo & 1,94 & 0,93 & 1,89 & 0,92 & 2,00 & 0,91 & 1,86 & 0,64 & 2,68 & 1,25 & 2,03 & 0,96 \\
\hline Condutas típicas & 1,86 & 0,73 & 1,68 & 0,70 & 1,90 & 0,84 & 1,73 & 0,70 & 2,09 & 0,97 & 1,84 & 0,78 \\
\hline Deficiência auditiva & 1,75 & 0,87 & 1,50 & 0,65 & 1,67 & 0,76 & 1,50 & 0,60 & 1,76 & 0,89 & 1,64 & 0,77 \\
\hline Deficiência física & 1,52 & 0,79 & 1,32 & 0,53 & 1,57 & 0,77 & 1,41 & 0,73 & 1,57 & 0,68 & 1,47 & 0,71 \\
\hline Deficiência mental & 2,20 & 1,08 & 2,05 & 1,01 & 2,27 & 1,08 & 1,95 & 0,92 & 2,45 & 1,22 & 2,18 & 1,06 \\
\hline Deficiência múltipla & 2,28 & 1,11 & 2,08 & 1,00 & 2,23 & 1,04 & 2,09 & 0,92 & 2,68 & 1,32 & 2,26 & 1,08 \\
\hline Deficiência visual & 1,76 & 1,01 & 1,61 & 0,72 & 1,80 & 0,76 & 1,64 & 0,73 & 2,14 & 1,21 & 1,76 & 0,90 \\
\hline Síndrome de Down & 1,88 & 0,86 & 1,84 & 1,01 & 1,83 & 0,91 & 1,59 & 0,59 & 2,18 & 1,10 & 1,86 & 0,92 \\
\hline Superdotação & 1,71 & 0,78 & 1,71 & 0,90 & 1,77 & 0,94 & 1,50 & 0,51 & 2,05 & 1,00 & 1,74 & 0,84 \\
\hline Surdocegueira & 2,08 & 1,04 & 1,89 & 0,92 & 2,07 & 0,94 & 1,91 & 0,87 & 2,32 & 1,29 & 2,04 & 1,01 \\
\hline
\end{tabular}


Tabela 4. ANOVA do nível de concordância de graduandos em Psicologia quanto à inclusão escolar de NEE por período.

\begin{tabular}{lccc}
\hline \multirow{2}{*}{ NEE } & \multicolumn{3}{c}{ ANOVA } \\
\cline { 2 - 4 } & $\mathrm{F}$ & $\mathrm{p}$ & $\mathrm{gl}$ \\
\hline Autismo & 3,13 & 0,02 & 4 \\
\hline Condutas típicas & 1,12 & 0,35 & 4 \\
\hline Deficiência auditiva & 0,87 & 0,48 & 4 \\
\hline Deficiência física & 0,80 & 0,53 & 4 \\
\hline Deficiência mental & 0,79 & 0,53 & 4 \\
\hline Deficiência múltipla & 1,22 & 0,30 & 4 \\
\hline Deficiência visual & 1,36 & 0,25 & 4 \\
\hline Síndrome de Down & 1,18 & 0,32 & 4 \\
\hline Superdotação & 1,21 & 0,31 & 4 \\
\hline Surdocegueira & 0,73 & 0,57 & 4 \\
\hline
\end{tabular}

Farrell (2004) destaca que as atitudes do psicólogo escolar em relação às NEE e à educação inclusiva podem influenciar no processo de inclusão. O psicólogo pode fazer uma grande diferença no processo inclusivo por meio de trabalhos e orientações com pais e professores, mostrando os benefícios e a eficácia da educação inclusiva, além de desenvolver programas individuais de trabalho e realizar adaptações curriculares (Farrell, 2004). Ao considerarem que certas NEE podem ser mais "incluídas" que outras, os futuros psicólogos revelam que terão dificuldade para concretizar o proposto por Farrell (2004, p. 11): "fazer a diferença na inclusão".

Há que se retomar que um dos principais objetivos do estudo em questão foi o de analisar a preparação recebida na graduação em Psicologia para atuar profissionalmente na educação inclusiva. Contudo, apesar de os resultados obtidos serem coerentes com os apresentados pela reduzida literatura sobre o assunto, é importante ressaltar que o presente estudo possui limitações. Uma delas diz respeito ao fato de os participantes terem sido recrutados em somente duas instituições de ensino superior de uma cidade do interior de Minas Gerais que oferecem o curso de graduação em Psicologia. Outra se refere ao delineamento transversal, por consequência, não longitudinal do estudo.

Ainda no âmbito das limitações da presente investigação, é preciso reiterar que a produção científica sobre a formação inicial em Psicologia para a educação inclusiva é muito restrita tanto no Brasil quanto em outros países. Este fato restringe sobremaneira a análise dos resultados obtidos.

Não obstante as ponderações dos dois parágrafos anteriores, os resultados encontrados podem ser considerados relevantes para todas as instituições que têm graduação em Psicologia, já que eles indicam que elas devem repensar a estrutura curricular dos cursos se a meta for formar profissionais para atuar em escolas inclusivas. Uma atenção especial deve ser dada aos estágios em Psicologia Escolar, que devem ir além do conteúdo curricular tradicional. Ao estagiar, é necessário que os futuros psicólogos tenham experiências significativas com inclusão escolar e que desenvolvam ainda mais atitudes positivas em relação à educação inclusiva. Só assim poderão fazer a diferença no processo que almeja estabelecer uma escola que garanta o acesso, a permanência e o sucesso para todos os estudantes, com e sem NEE.

\section{Referências}

Ajzen, I. (2001). Nature and operation of attitudes. Annual review of Psychology, 52(1), 27-58.

Andrada, E. G. C. (2005). Novos paradigmas na prática do psicólogo escolar. Psicologia: reflexão e crítica, Porto Alegre, 18(2), (paginação irregular).

Angelides, P., Stylianou, T., \& Gibbs, P. (2006). Preparing teachers for inclusive education in Cyprus. Teaching and teacher education, 22, 513-522.

Bariani, I. C. D., Buin, E., Barros, R. C., \& Escher, C. A. (2004). Psicologia escolar educacional no ensino superior: análise da produção científica. Psicologia Escolar e Educacional, 8, 17-27.

Bock, A. (2005). Apresentação. Em A. M. Machado e cols., Psicologia e direitos humanos: educação inclusiva - direitos humanos na escola. São Paulo: Casa do Psicólogo. 
Carroll, A., Forlin, C., \& Jobling. A. (2003). The impact of teacher training in special education on the attitudes of australian preservice general educators towards people with disabilities. Teacher education quarterly, 30(3), 65-79.

Colli, F. A. G. (2005). O Grupo Ponte. F. A. G. Colli \& M. C. M. Kupfer (Orgs.), Travessias: inclusão escolar - a experiência do Grupo Ponte/ Pré-escola Terapêutica Lugar de Vida (pp.29-33). São Paulo: Casa do Psicólogo.

Colli, F. A. G., \& Kupfer, M. C. M. (Orgs.). (2005) Travessias: inclusão escolar - a experiência do Grupo Ponte/ Pré Escola Terapêutica Lugar de Vida. São Paulo: Casa do Psicólogo.

Conselho Nacional de Educação. (2004). Diretrizes Curriculares Nacionais para os cursos de graduação em Psicologia. Psicologia: teoria e pesquisa, 20(2), 205-208.

Conselho Federal de Psicologia. (2004). Relatório de gestão. Recuperado: 10 mai 2007. Disponível: http://www.pol.org.br/ publicacoes/pdf/relatorio_gestao.pdf

Conselho Federal de Psicologia. (2006). Prêmio: "Educação Inclusiva: experiências profissionais em Psicologia". Recuperado: 10 mai 2007. Disponível: http://www.pol.org.br/noticias/materia. cfm?id=664\&materia $=994$

Crano, W. D., \& Prislin, R. (2006). Attitudes and persuasion. Annual review of Psychology, 57, 345-374.

Engelbrecht, P. (2004). Education in South Africa: changing roles for educational psychologists within inclusive. School Psychology International, 25(1), 20-29.

Farrell, P. (2004). Making inclusion a reality for all. School Psychology International, 25(1), 5-19.

González, J. A. T. (2002). Educação e diversidade: bases didáticas e organizativas. Porto Alegre: ARTMED.

Hastings, R. P., \& Oakford, S.(2003). Student teacher's attitudes towards the inclusion of children with special needs. Educational Psychology, 23(1), (paginação irregular).

Instituto Brasileiro de Geografia e Estatística - IBGE. (2000). Censo Demográfico 2000. Recuperado: 20 set 2007. Disponível: http:// www.ibge.gov.br/home/estatistica/populacao/censo2000/

INEP (2006). Censo Escolar 2006. Recuperado: 10 set 2007. Disponível: http://www.inep.gov.br.

Johnson, G. M., \& Howel, A. J. (2005). Change in pre-service teacher attitudes toward contemporary issues in education. ERIC Digest. Recuperado: 10 mai 2007. Disponível: http://eric.ed.gov/ ERICDocs/data/ericdocs2/content_storage_01/0000000b/80/31/ bd/3c.pdf
Kafrouni, R., \& Pan, M. A. G. S. (2001). A inclusão de alunos com necessidades educativas especiais e os impasses frente à capacitação dos profissionais da educação básica: um estudo de caso. Inclusão de alunos com necessidades especiais e educação básica. Interação, 5, 31-46.

Machado, A. M. e cols. (2005). Psicologia e direitos humanos: educação inclusiva - direitos humanos na escola. São Paulo: Casa do Psicólogo.

Ministério da Educação. Inep. (2006). Censo Escolar 2006. Recuperado: 20 set 2007. Disponível: http://portal.mec.gov.br/ seesp/index.php?option=content\&task=view\&id=62\&ltemid=191.

Mendes, E. G. (2006). Colaboração entre ensino regular e especial: o caminho do desenvolvimento pessoal para a inclusão escolar. Em E. J. Manzini (Org.), Inclusão e acessibilidade (pp.29-41). Marília, SP: ABPEE.

Ministério da Saúde. CONEP. (1996). Conselho Nacional de Saúde. Resolução 196/1996. Diretrizes e normas regulamentadoras de pesquisas envolvendo seres humanos. Brasília: Ministério da Saúde.

Mitjáns Martínez, A.(2005). Inclusão escolar: desafios para o psicólogo. Em A. Mitjáns Martinez (Org.), Psicologia Escolar e compromisso social (pp. 95-114). Campinas, SP: Alínea.

Neves, M. M. B. J., Almeida, S. F. C., Chaperman, M. C. L., \& Batista, B. P. (2002). Formação e atuação em Psicologia: análise das modalidades de comunicações nos Congressos Nacionais de Psicologia Escolar e Educacional. Psicologia ciência e profissão, 22(2), 2-11.

Omote, S. (2005). A construção de uma escala de atitudes sociais em relação à inclusão: notas preliminares. Revista Brasileira de Educação Especial, 11(1), 33- 47.

Senna, R. C. M., \& Almeida, S. F. C. (2005). Formação e atuação do psicólogo escolar da rede pública de ensino do Distrito Federal: panorama atual e perspectivas futuras. Em A. M. Martinez (Org.), Psicologia Escolar e compromisso social (pp. 199-230). Campinas, SP: Alínea.

Martinez (Org.), Psicologia Escolar e compromisso social (pp. 199230). Campinas, SP: Alínea

Unesco. (1994). Declaração de Salamanca - Sobre Princípios, Políticas e Práticas na Área das Necessidades Educativas Especiais. Recuperado: 05 mai 2007. Disponível: http://portal. mec.gov.br/seesp/arquivos/pdf/salamanca.pdf

Voltz, D. L. (2001). Preparing general education teachers for inclusive Settings. Learning disability quarterly, 24(4), 288-296. 
Recebido em: 09/02/2009

Reformulado em: 04/10/2010

Aprovado em: 21/09/2011

\section{Sobre os autores}

Altemir José Gonçalves Barbosa (altgonc@uol.com.br)

Professor do Curso de Psicologia e do Programa de Pós-Graduação em Psicologia da UFJF Mestre em Psicologia Escolar e Doutor em Psicologia - PUC-Campinas

Rua Santos Dumont, 214 - Granbery - Juiz de Fora/MG - CEP: 36010-510 - Telefone: (32)3216-1029

Carolina Ferreira Conti (carolfconti@yahoo.com.br)

Mestranda em Psicologia da UFJF

Graduada em Psicologia - UFJF

Endereço para correspondência:

Rua São Mateus, 755/1802 - São Mateus - Juiz de Fora/MG CEP: 36025-001 - Telefone: (32) 3232-8927 - Fax: (32) 32178253 